\title{
A Study on the Properties of Poly (Styrene-co-Methyl Methacrylate)/Silica Aerogel Nanocomposites Prepared via in situ SR\&NI ATRP
}

\author{
Khezrollah Khezri ${ }^{1}$ and Yousef Fazli ${ }^{2, *}$ \\ ${ }^{1}$ Young Researchers and Elite Club, Central Tehran Branch, Islamic Azad University, Tehran, Iran \\ ${ }^{2}$ Department of Chemistry, Faculty of Science, Arak Branch, Islamic Azad University, Arak, Iran, \\ P.O. Box 14155-6455, Tel: +988633412603 \\ *Corresponding author: E-mail:yousefffazli75@gmail.com; y-fazli@iau-arak.ac.ir
}

Received: 30-08-2018

\begin{abstract}
Simultaneous reverse and normal initiation technique for atom transfer radical copolymerization (SR\&NI ATRP) of styrene and methyl methacrylate in the presence of hexamethyldisilazane (HMDS)-modified silica aerogel nanoparticles (H-SAN) and investigating the effect of addition of H-SAN on the copolymerization and thermal properties of the products are discussed. Some unique features of the H-SAN are evaluated using nitrogen adsorption/desorption isotherm, SEM and TEM. Conversion and molecular weight determinations were carried out using GC and SEC respectively. Adding of $\mathrm{H}$-SAN by $3 \mathrm{wt} \%$ results in decrement of conversion from 94 to $73 \%$. In addition, molecular weight of copolymer chains decreases from 19500 to 16000 g. mol ${ }^{-1}$. However, polydispersity index values increases from 1.29 to 1.65 . Linear increase of $\ln \left(\mathrm{M}_{0} / \mathrm{M}\right)$ with time for all the samples shows that copolymerization proceeds in a living manner. Increasing thermal stability of the nanocomposites is demonstrated by TGA. DSC results show a decrease in glass transition temperature from 70.3 to $63.5^{\circ} \mathrm{C}$ by addition of $3 \mathrm{wt} \% \mathrm{H}-\mathrm{SAN}$.
\end{abstract}

Keywords: Nanocomposite; kinetics study; silica aerogel nanoparticles; poly (styrene-co-methyl methacrylate); SR\&NI ATRP

\section{Introduction}

Nanocomposites are new class of materials that can combine the inherent properties of the organic phase (such as dielectric, ductility and processability) and inorganic phase (such as rigidity and thermal stability). ${ }^{1-3}$ Usage of nanoscale materials with small size and large interfacial area per unit volume results in nanocomposites possess unique features in which are not provided by traditional composites. ${ }^{4-6}$ For example, polymer layered silicate nanocomposites present improvements in various properties (such as strength, thermal expansion coefficient, barrier, flammability resistance, environmental stability, and etc) in comparison with unmodified polymer. ${ }^{4,7}$ Due to the unique features of the nanocomposites, they can be employed in diverse applications such as electronics, adhesives, and automotive fields. ${ }^{8}$ In situ polymerization, solution blending and melt intercalation are three famous methods for the preparation of polymer nanocomposites. ${ }^{9}$ Incorporation of tailor-made polymers (organic phase) for the preparation of nanocom- posites is an attractive topic since the molecular features of the organic phase can be tailored and some specific properties of the resulting hybrid can be dictated. ${ }^{10}$

Aerogels are highly porous materials with surface areas between 500 and $1600 \mathrm{~m}^{2} / \mathrm{g}$ and densities between 0.002 and $0.8 \mathrm{~g} / \mathrm{cm}^{3}$. Aerogels present unique physical properties that have made them attractive and many useful for thermal and acoustic insulation, low constant dielectric materials, and Cherenkov radiation counters. ${ }^{11-14}$ Silica aerogels are consisting of about $99 \%$ air and $1 \%$ solid silica in the form of highly cross-linked network structure (three-dimensional network of nanoparticles). ${ }^{15-17}$ Large surface area, high degree of porosity, very low bulk density, very low thermal conductivity, high optical transmission, low refractive index, and low sound velocity are some unique properties of the silica aerogels that make them appropriate potential candidate for many applications (e.g. thermal insulation, drug delivery system, catalysis, adsorption, and etc). ${ }^{11,16,18-21}$

Application of various initiation techniques can be considered as one the main advantages of ATRP over other 


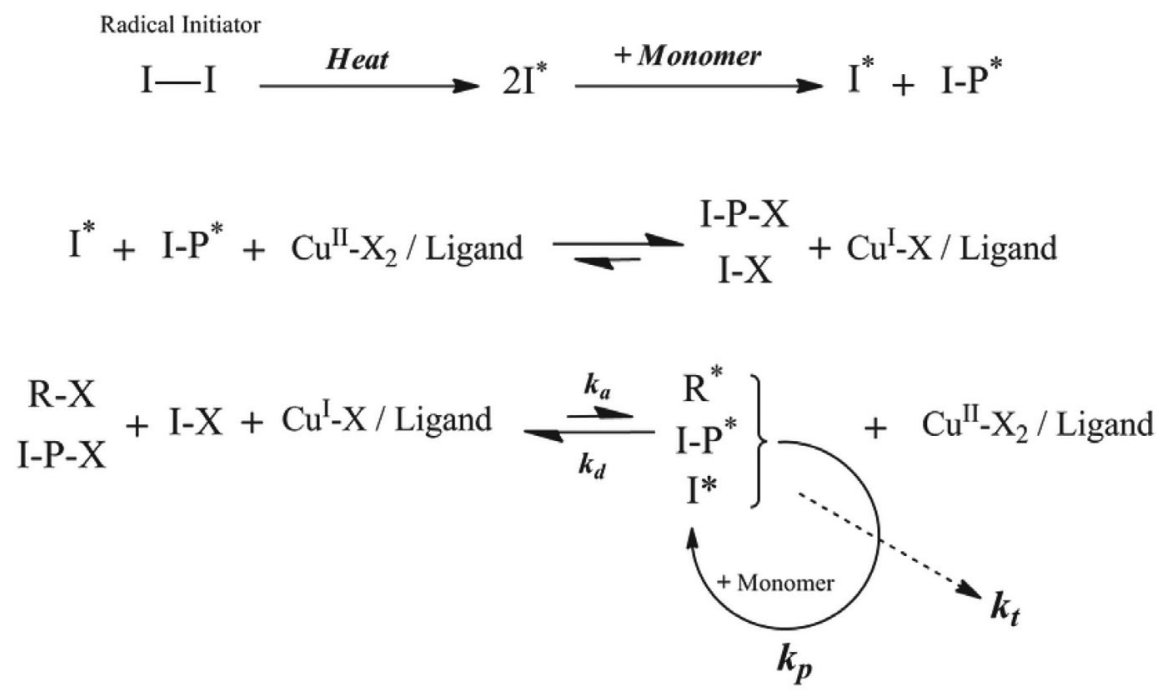

Figure 1. Schematic mechanism for SR\&NI ATRP

the controlled living radical polymerization (CLRP) methods. SR\&NI ATRP as an interesting initiation technique for ATRP is developed since it can provide many useful characteristics such as application low concentration of transition metal complex, application of transition metal complex in its higher oxidation state $\left(\mathrm{CuBr}_{2}\right)$, and its ability to produce pure block copolymer. ${ }^{22-23}$ Schematic mechanism of SR\&NI ATRP is presented in figure 1.

Reviewing related literature indicates that some studies have been done on the synthesis and investigating properties of silica aerogel/polymer nanocomposites. ${ }^{24-28}$ Application of various initiation techniques for ATRP in the presence of different nano-fillers (e.g. clay and diatomite) were also reported previously. ${ }^{29-31}$ In this study, pristine silica aerogel nanoparticles were modified by HMDS as a surface modifier agent and hydrophobic silica aerogel nanoparticles were obtained. Abundant advantages of SR\&NI ATRP were employed to synthesize well-defined poly (styrene-co-methyl methacrylate) nanocomposites. Investigating the effect of $\mathrm{H}$-SAN addition on the polymerization parameters (conversion, molecular weight, and PDI values) are carefully performed. By these results it can be concluded that increment of H-SAN in the polymerization media how can affect the polymerization kinetics (positive effect of negative effect). In addition, thermal properties of the prepared nanocomposites are studied in detail. By these results it can be comprehended that addition of H-SAN in the polymer matrix how can improve thermal features of the nanocomposites in comparison with the neat polymer.

\section{Experimental}

\section{1. Materials}

Styrene (St, Aldrich, 99\%) and methyl methacrylate (MMA, Merck, 99\%) were passed through an alumina filled column to remove inhibitors. Copper(I) bromide (CuBr, Aldrich, 98\%), N,N, $\mathrm{N}^{\prime}, \mathrm{N}^{\prime \prime}, \mathrm{N}^{\prime \prime}$-pentamethyldiethylenetriamine (PMDETA, Aldrich, 99\%), ethyl alpha-bromoisobutyrate (EBiB, Aldrich, 97\%), 2,2'-azobisisobutyronitrile (AIBN, Acros), anisole (Aldrich, 99\%), tetrahydrofuran (THF, Merck, 99\%), neutral aluminum oxide (Aldrich, 99\%), tetraethoxysilane (TEOS, Merck), n-hexane (Merck), Ethanol (EtOH, Merck, 99\%), oxalic acid (Aldrich, >99\%), ammonium hydroxide (Tabriz Petrochemical Company) and hexamethyldisilazane (HMDS, Merck) were used as received.

\section{2. Synthesis of Hydrophilic and HMDS- modified Silica Aerogel Nanoparticles}

Pristine and H-SAN were prepared according to the procedure as reported previously. ${ }^{20,32}$

\section{3. SR\&NI Atom Transfer Random Radical Copolymerization of Styrene and Methyl Methacrylate}

Typical batch of copolymerization was run at $110^{\circ} \mathrm{C}$ with the molar ratio of 200:1:0.2:0.2:0.12 for $[\mathrm{M}]:[\mathrm{EBiB}]:\left[\mathrm{CuBr}_{2}\right]$ :[PMDETA]:[AIBN] giving a theoretical molecular weight of 20457 g.mol ${ }^{-1}$ at final conversion. At first, styrene $(0.073 \mathrm{~mol}, 8.34 \mathrm{ml})$, methyl methacrylate (0.058 mol, $6.2 \mathrm{ml}), \mathrm{CuBr}_{2}(0.17 \mathrm{mmol}, 0.039 \mathrm{~g})$, PMDETA $(0.17 \mathrm{mmol}, 0.03 \mathrm{ml})$ and anisole $(10 \mathrm{ml})$ were added to the reactor. Then, it was degassed and back-filled with nitrogen three times, and then left under $\mathrm{N}_{2}$ with stirring at room temperature. After that, reaction temperature was increased to $110^{\circ} \mathrm{C}$ during $5 \mathrm{~min}$. Subsequently, predeoxygenated solution of AIBN $(0.1 \mathrm{mmol}, 0.017 \mathrm{~g})$ in the styrene $(0.043 \mathrm{~mol}, 5 \mathrm{ml})$ and predeoxygenated $\mathrm{EBiB}(0.87$ $\mathrm{mmol}, 0.12 \mathrm{ml})$ were injected into the reactor to start the copolymerization reaction. At the beginning of the reac- 
tion, copolymerization media was green and gradually changed to brown. Samples were taken at the end of the reaction to measure the final conversion.

\section{4. Preparation of Poly (Styrene-co- methyl Methacrylate)/Silica Aerogel Nanocomposites by in Situ SR\&NI ATRP}

For preparation of nanocomposites, a desired amount of H-SAN was dispersed in $7 \mathrm{ml}$ of styrene and the mixture was stirred for 17 hours. Then, the remained 1.34 $\mathrm{ml}$ of styrene was added to the mixture. Subsequently, copolymerization procedure was applied accordingly. Designation of the samples with the percentage of modified silica aerogel nanoparticles is given in table 1 .

\section{5. Characterization}

Materials porosity was characterized by $\mathrm{N}_{2}$ adsorption/desorption curves obtained with a Quntasurb QS18 (Quntachrom) apparatus. The surface area and pore size distribution values were obtained with the corrected BET equation (Brunauer-Emmett-Teller). Surface morphology of the samples was examined by Scanning Electron Microscope (SEM, Philips XL30) with acceleration voltage of 20 $\mathrm{kV}$. Also, transmission electron microscope (TEM, FEG Philips CM) with an accelerating voltage of $200 \mathrm{kV}$ was used. Gas chromatography (GC) is a simple and highly sensitive characterization method and does not require removal of the metal catalyst particles. GC was performed on an Agilent-6890N with a split/splitless injector and flame ionization detector, using a $60 \mathrm{~m}$ HP-INNOWAX capillary column for the separation. The GC temperature profile included an initial steady heating at $60{ }^{\circ} \mathrm{C}$ for 10 min and a $10^{\circ} \mathrm{C} / \mathrm{min}$ ramp from 60 to $160^{\circ} \mathrm{C}$. The samples were also diluted with acetone. The ratio of monomer to anisole was measured by GC to calculate monomer conversion throughout the reaction. Size exclusion Chromatography (SEC) was used to measure the molecular weight and molecular weight distribution. A Waters 2000 ALLIANCE with a set of three columns of pore sizes of 10000 , 1000 , and $500 \AA$ was utilized to determine polymer average molecular weight and polydispersity index (PDI). Thermal gravimetric analysis (TGA) was carried out with a PL thermo-gravimetric analyzer (Polymer Laboratories, TGA 1000, UK). Thermograms were obtained from ambi- ent temperature to $700{ }^{\circ} \mathrm{C}$ at a heating rate of $10^{\circ} \mathrm{C} / \mathrm{min}$. Thermal analysis were carried out using a differential scanning calorimetry (DSC) instrument (NETZSCH DSC 200 F3, Netzsch Co, Selb/Bavaria, Germany). Nitrogen at a rate of $50 \mathrm{~mL} / \mathrm{min}$ was used as purging gas. Aluminum pans containing 2-3 mg of the samples were sealed using DSC sample press. The samples were heated from ambient temperature to $220^{\circ} \mathrm{C}$ at a heating rate of $10^{\circ} \mathrm{C} / \mathrm{min}$.

\section{Results and Discussion}

Nitrogen adsorption/desorption isotherm of the $\mathrm{H}$-SAN indicate that this material can be classified as a mesoporous type according to the IUPAC classification (figure 2). ${ }^{32}$

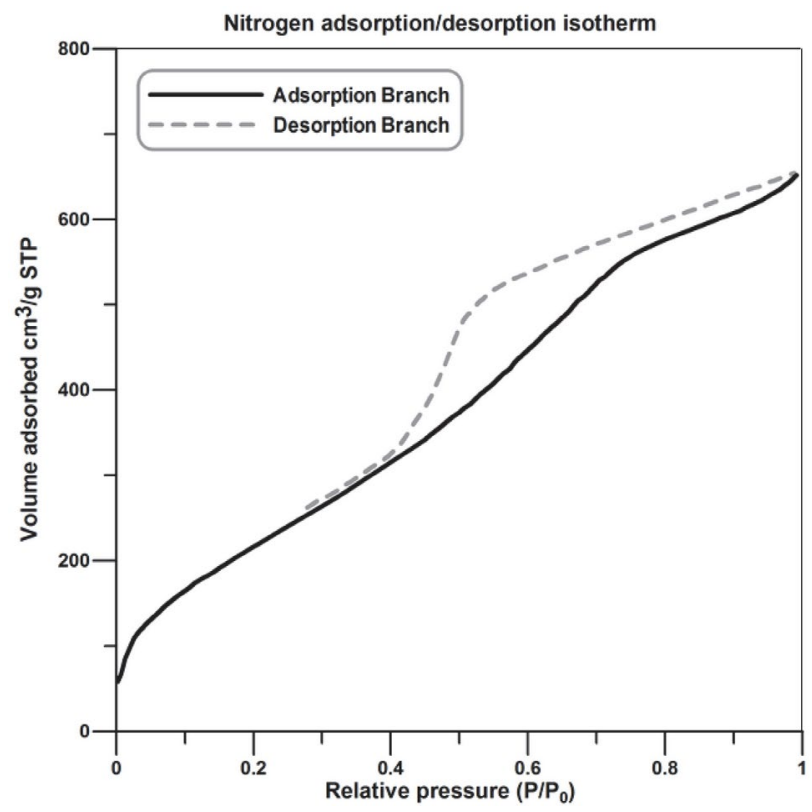

Figure 2. Nitrogen adsorption/desorption isotherm of the H-SAN

According to extracted data from nitrogen adsorption/desorption isotherm, BET surface area and average pore diameter of the synthesized aerogel (modified silica aerogel nanoparticles) are calculated $958.67 \mathrm{~m}^{2} / \mathrm{g}$ and 4.05 $\mathrm{nm}$ respectively.

TEM and SEM images of the H-SAN are displayed in figure 3. According to these images, H-SAN present

Table 1. Designation of the samples

\begin{tabular}{lccc}
\hline Sample & $\begin{array}{c}\text { Method of } \\
\text { Preparation }\end{array}$ & $\begin{array}{c}\text { Proportion of H-SAN } \\
(\mathbf{w t} \%)\end{array}$ & $\begin{array}{c}\text { Dispersion Time Prior to } \\
\text { the Copolymerization (h) }\end{array}$ \\
\hline PRSM & SR\&NI ATRP & 0 & - \\
RSMAC 1 & In situ SR\&NI ATRP & 1 & 17 \\
RSMAC 2 & In situ SR\&NI ATRP & 2 & 17 \\
RSMAC 3 & In situ SR\&NI ATRP & 3 & 17 \\
\hline
\end{tabular}



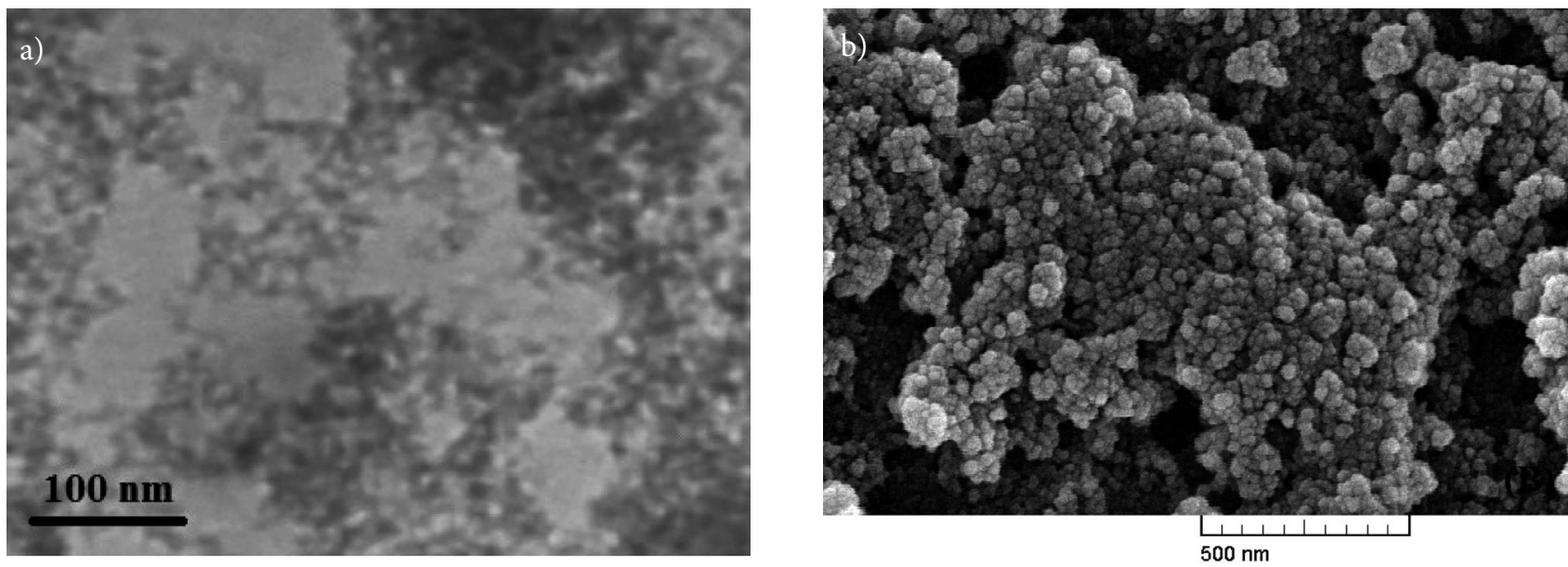

Figure 3. TEM (A) and SEM (B) images of the H-SAN

spongy structure and the particles are relatively mono-dispersed. In addition, average diameter of the particles is estimated around $25 \mathrm{~nm}$.
General procedure for the synthesis of tailor-made random poly (styrene-co-methyl methacrylate) chains via SR\&NI ATRP in the presence of H-SAN is shown in figure 4.

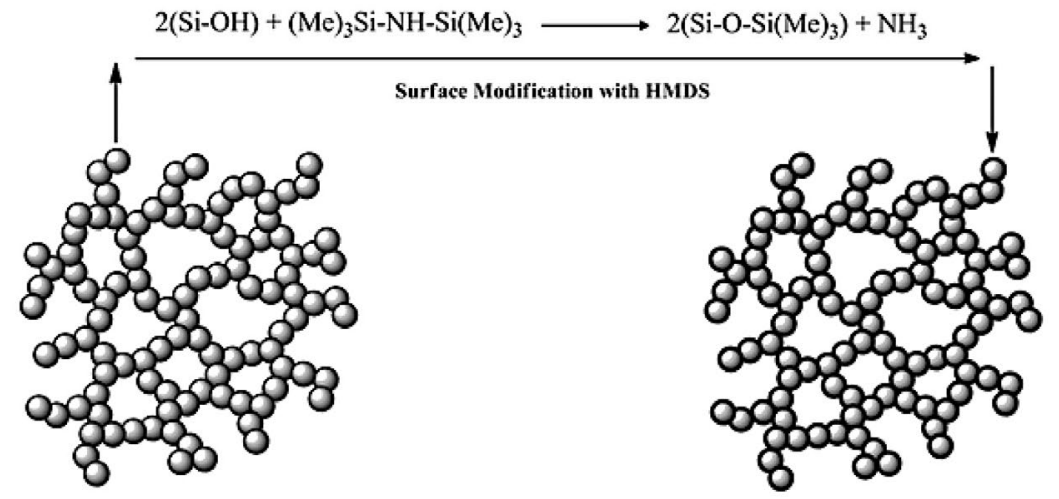

Hydrophile Silica Aerogel Nanoparticles

Hydrophobe Silica Aerogel Nanoparticles

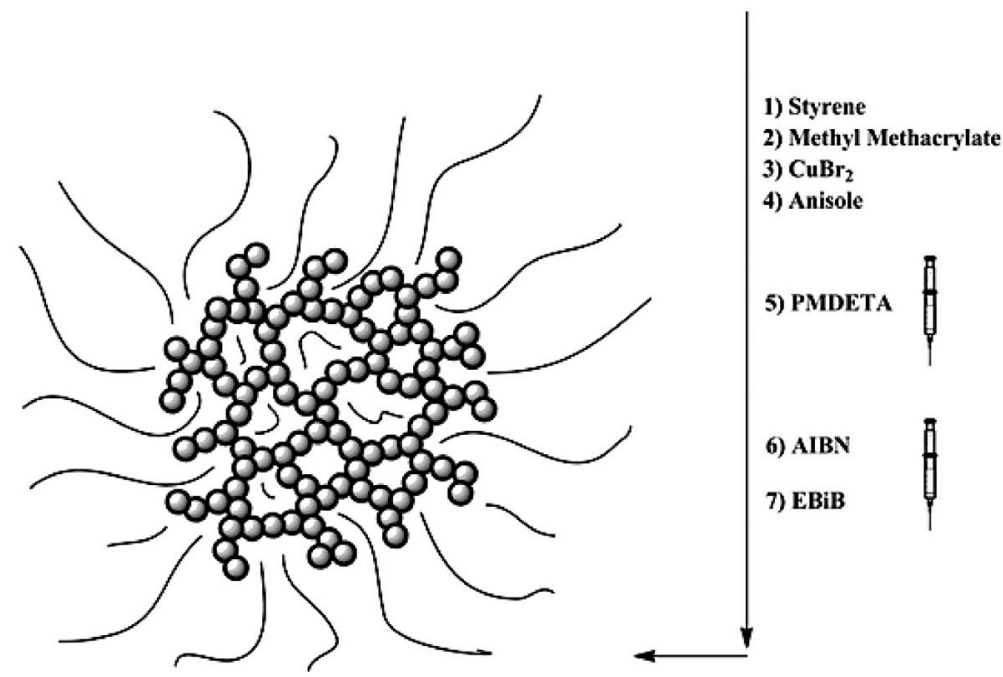

Poly (styrene-co-methyl methacrylate)/Hydrophobically modified Silica Aerogel Nanocomposite

Figure 4. General procedure for preparation of poly (styrene-co -methyl methacrylate)/H-SAN nanocomposites by in situ SR\&NI ATRP 
During the copolymerization process, monomer conversion with time can present various behaviors. Thus, examining the variation of conversion with time for the copolymerization system can be considered as an important parameter. Variation of monomers (MMA and St) conversion versus time for the neat poly (styrene-co-methyl methacrylate) and its different nanocomposites are presented in figure 5 . According to the results, by proceeding of the reaction, an increment in the conversion is obtained. Also, copolymerization of MMA and St without the modified silica aerogel nanoparticles results in higher conversion in various time steps. On the other hands, by increasing modified silica aerogel nanoparticles content lower monomer conversions are obtained (conversion: RSMAC $3<$ RSMAC $2<$ RSMAC $1<$ PRSM). These results indicate that presence of $\mathrm{H}-\mathrm{SAN}$ can result in negative effect on the copolymerization rate and final conversion of the monomers. Negative effect of the modified silica aerogel nanoparticles on the copolymerization may be attributed to the three main factors; i) Impurity role of the H-SAN: it is demonstrated that existence of some nano-fillers in the copolymerization media can disturb the ATRP equilibrium and therefore products with lower conversion, lower molecular weights, and higher PDI values can be prepared. ${ }^{33-35}$ ii) Restriction of the mobility: due to the porous structure of the H-SAN, mobility of the radicals and growing macro-radicals in the solution can be restricted and therefore copolymerization rate and monomers conversion can be decreased. It is clear that by increasing modified silica aerogel nanoparticles content, more restriction will be happened and therefore higher decrement in the conversion can be obtained. ${ }^{41-43}$ iii) Irreversible reactions: It is demonstrated that growing radicals in the copolymerization media can irreversibly react with various functional moieties. Thus, growing radicals can irreversibly react with the moieties (such as un-modified hydroxyl groups) on the H-SAN and therefore can present negative effect on the copolymerization rate and conversion. ${ }^{33-35}$

Variation of number-averaged molecular weight $(\mathrm{Mn})$ with conversion during the copolymerization is represented in figure 6. Theoretical line in this figure is displayed to present theoretical $\mathrm{Mn}$ values for the various conversions. As it can be expected, in the neat copolymer and different nanocomposites by increasing conversion copolymer chains with higher Mn were obtained. According to the results, PRSM has higher Mn values in comparison with the different nanocomposites (RSMAC 1-3). On the other hands, addition of the H-SAN in the copolymerization media results in decrement of $\mathrm{Mn}$ of the products. By increasing H-SAN content, more decrement in $\mathrm{Mn}$ is observed (Mn: PRSM > RSMAC $1>$ RSMAC $2>$ RSMAC 3 ). This negative effect of the H-SAN on the molecular weight of the copolymer chains can be also attributed to the three above mentioned reasons (impurity role, restric-

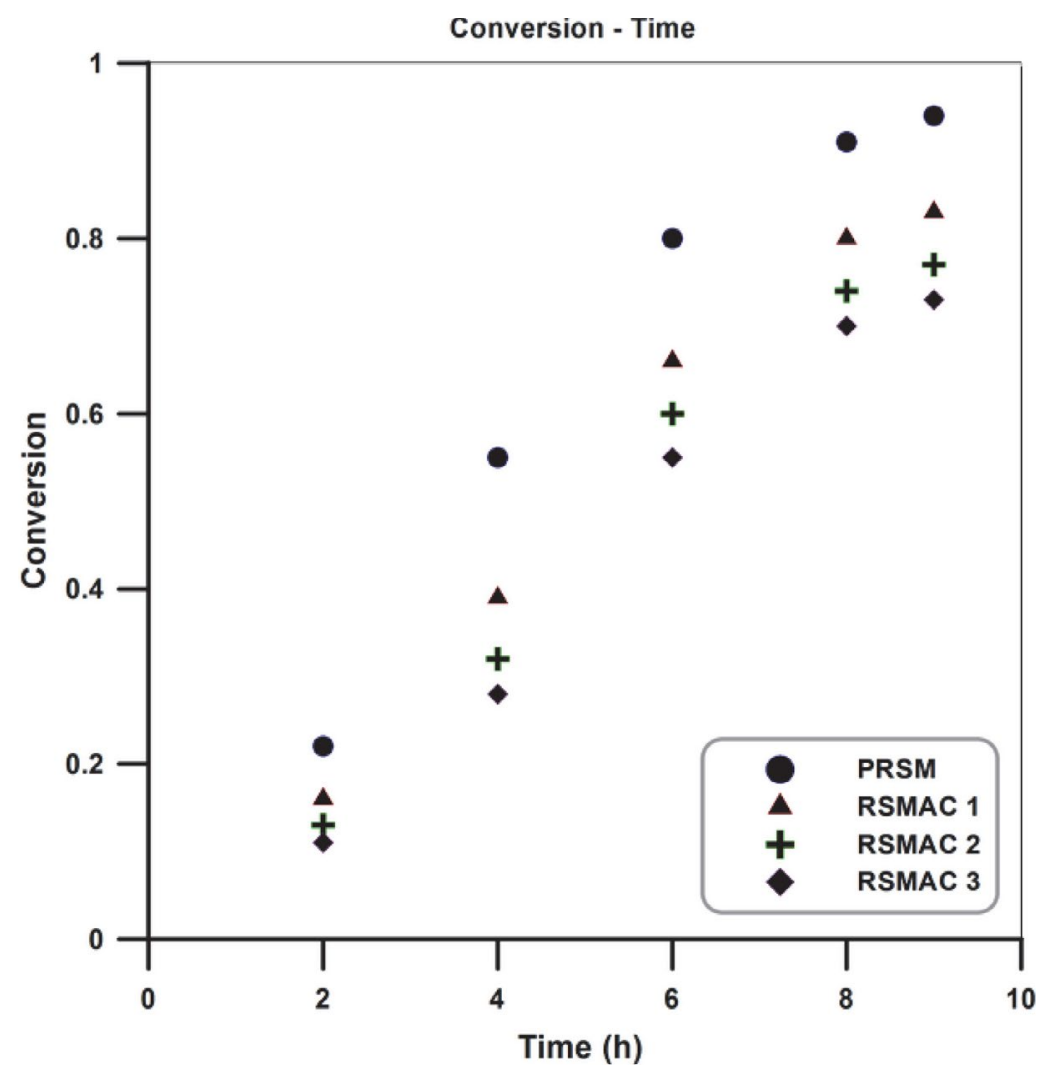

Figure 5. Variation of monomers conversion with time for the PRSM and RSMAC 1-3 


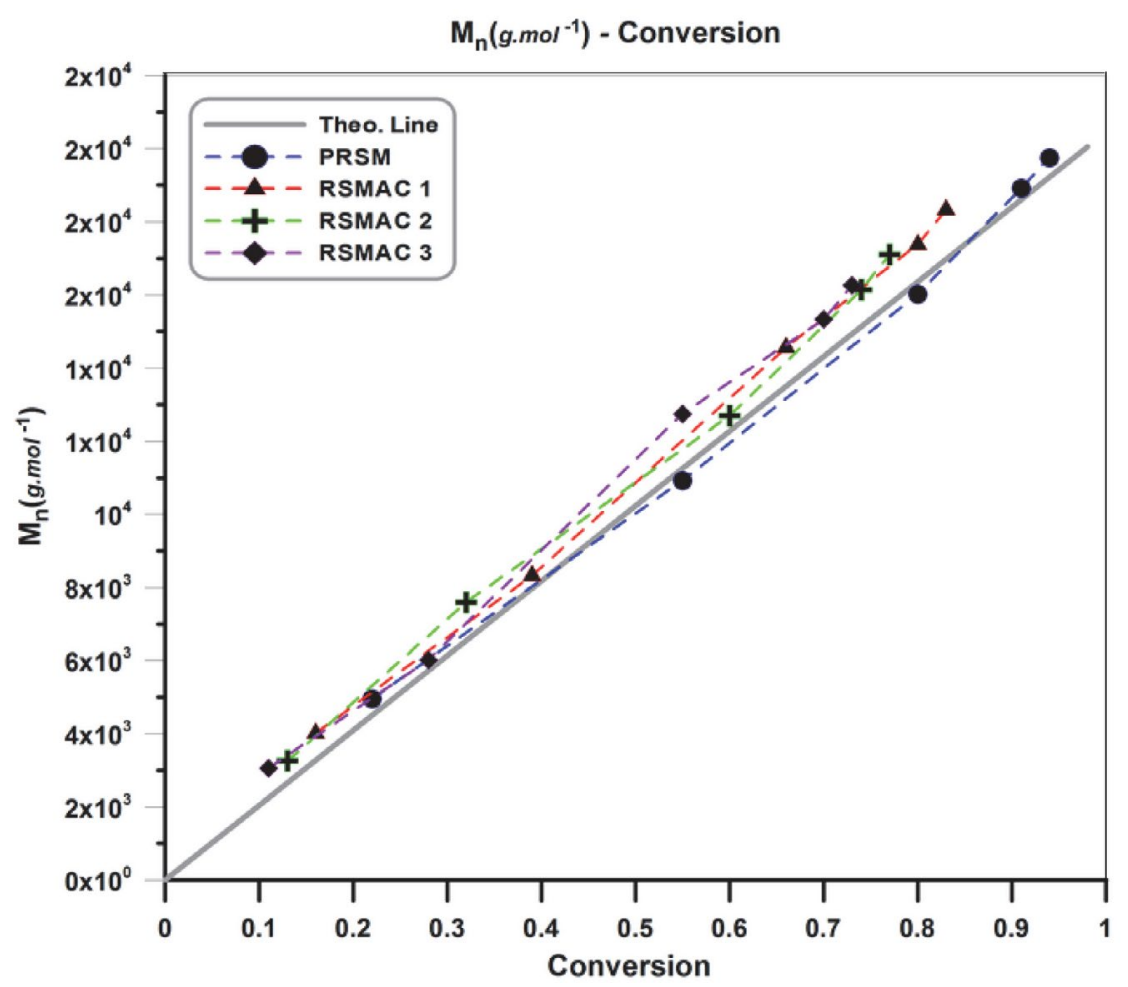

Figure 6. Variation of molecular weight versus conversion for the PRSM and RSMAC 1-3

tion of the mobility, and irreversible reactions). ${ }^{33-35}$ By precise evaluation of the results an appropriate agreement between experimental and theoretical Mn values are observed that this agreement can be considered as a suitable evidence for demonstration of the living nature of the copolymerization system.

Variation of PDI values with conversion for the neat copolymer and its various nanocomposites is displayed in figure 7. Since the copolymerization system (SR\&NI ATRP) is a member of CLRP family, it could be predicted that PDI values present a decrement by proceeding of the reaction (by increasing of conversion). Although addition of nano-fillers can affect CLRP equilibrium, they can not change the living nature of the system and therefore a decrement in PDI values by increasing conversion are observed in the pure copolymer (PRSM) and its different nanocomposites (RSMAC 1-3). According to the figure 7, PDI value of the PRSM is lower than RSMAC 1-3. In the nanocomposites, by increasing modified silica aerogel nanoparticles content higher PDI values are obtained (PDI: PRSM $<$ RSMAC $1<$ RSMAC $2<$ RSMAC 3). Increment of PDI values by increasing $\mathrm{H}$-SAN content can be attributed to the impurity role of the H-SAN. The occurrence of termination and transfer reactions between the propagating (macro)radicals and H-SAN can be considered as the main reason of emerging high PDI values in the nanocomposites samples. ${ }^{33-35}$

Figure 8 shows pseudo-first-order kinetic plots for the synthesized nanocomposites and the neat copolymer.

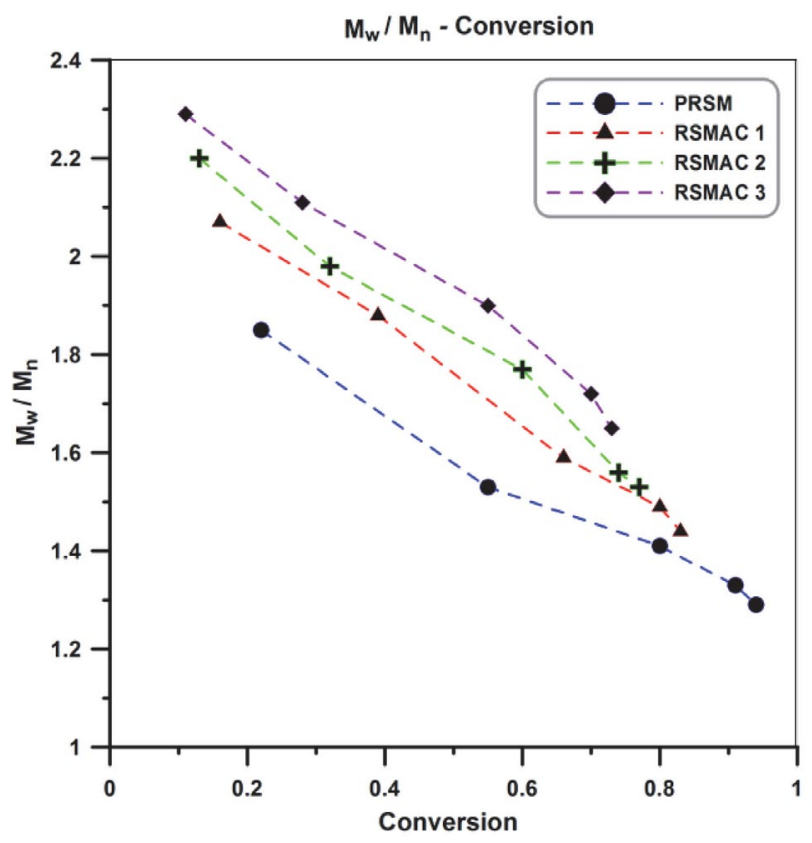

Figure 7. Variation of PDI values with conversion for the PRSM and RSMAC 1-3

Results indicate that the slope of the curves (PRSM and RSMAC 1-3) remains fairly constant in the whole of the copolymerization and therefore it can be concluded that steady-state kinetics for all of the samples is obtained. According to the figure, PRSM and RSMAC 1-3 present lin- 


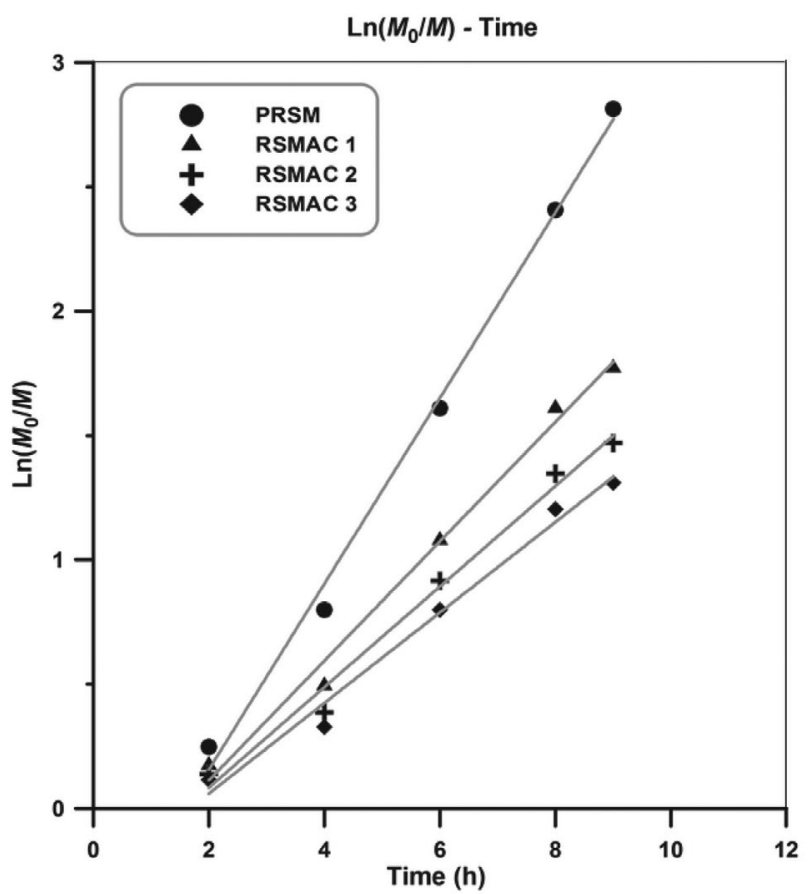

Figure 8. Kinetic plots with respect to the reaction time

early increment of $\operatorname{Ln}\left(\mathrm{M}_{0} / \mathrm{M}\right)$ with time in which constant radical concentration in the copolymerization media can be concluded. ${ }^{33-34}$ Results also indicate that by increasing H-SAN content a considerable decrement in the copolymerization rate will be obtained.

PRSM and RSMAC 1-3 display monomodal peak in their SEC traces (figure 9). According to this figure, PRSM presents narrow distribution in comparison with the RSMAC 1-3. Also, by increasing H-SAN loading broaden distribution are obtained (molecular weight distribution: PRSM $<$ RSMAC $1<$ RSMAC $2<$ RSMAC 3 ).

SEC traces demonstrate that SR\&NI ATRP of MMA and $\mathrm{St}$ in the presence of $\mathrm{H}$-SAN results in copolymer with broaden molecular weight distribution. On the other hands, absence of the H-SAN in the copolymerization media leads to copolymer with lower PDI values. As it mentioned above, H-SAN can disturb the equilibrium of SR\&NI ATRP due its three main roles (impurity role, restriction of the mobility, and irreversible reactions). ${ }^{33-35}$ According to the extracted data in table 2, by addition of 3 $\mathrm{wt} \%$ of the H-SAN monomer conversion decreases from

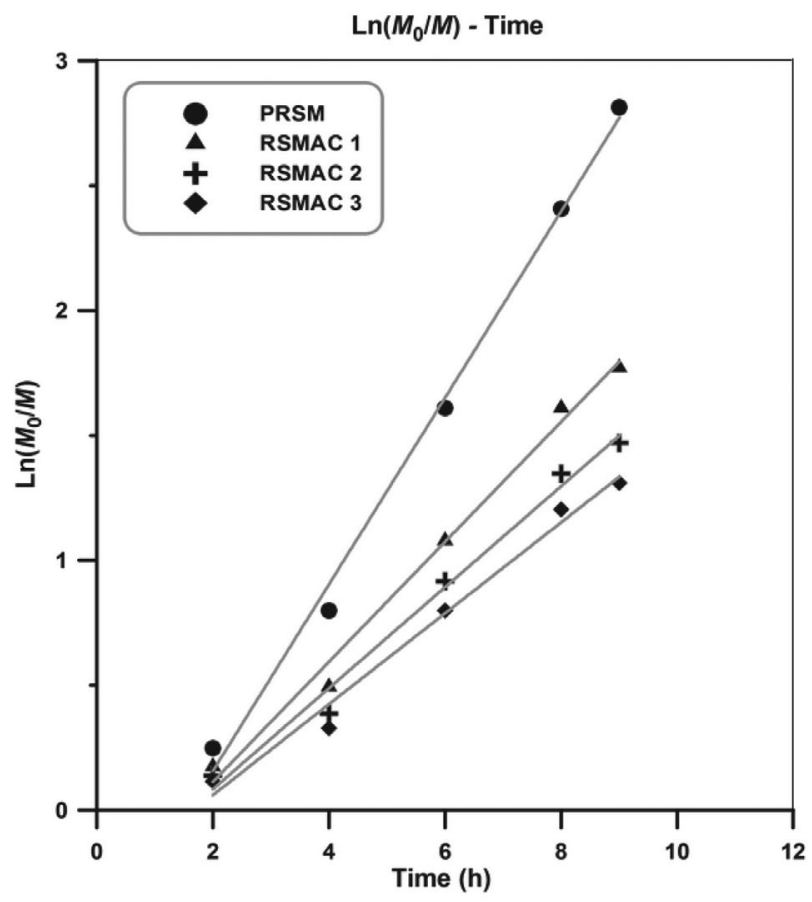

Figure 9. SEC traces of the neat random poly) styrene-co-methyl methacrylate) and its nanocomposites

$94 \%$ to $73 \%$. Meanwhile PDI values present an increment from 1.29 to 1.65 .

$$
M_{n}^{\text {Theo }}=\frac{[M]_{0}}{[E B i B]_{0}} \times \operatorname{Conv} . \times M w
$$

where, $[\mathrm{M}]_{0}$ and $[\mathrm{EBiB}]_{0}$ are initial concentration of the monomers and ATRP initiator, respectively. Conversion is denoted by Conv. and the symbol of the average molecular weight of the monomers is $\mathrm{M}_{\mathrm{w}}$.

TGA thermograms of the PRSM and RSMAC 1-3 in the temperature window of $25-700{ }^{\circ} \mathrm{C}$ in two different styles are displayed in figure 10 . Char values at $700{ }^{\circ} \mathrm{C}$ are also presented in this figure. As expected, by increasing $\mathrm{H}$-SAN content, char values of the prepared nanocomposites should be increased (char values: PRSM $<$ RSMAC $1<$ RSMAC $2<$ RSMAC 3 ).

Figure 10 indicates that thermal stability of the PRSM is lower than various nanocomposites. Also, it can be concluded that by increasing $\mathrm{H}$-SAN content, more im-

Table 2. Molecular weights and PDI values of the extracted copolymers resulted from SEC traces

\begin{tabular}{lcccccr}
\hline Sample & $\begin{array}{c}\text { Reaction } \\
\text { Time (h) }\end{array}$ & $\begin{array}{c}\text { Conversion } \\
\mathbf{( \% )}\end{array}$ & $\mathbf{E x p .}$ & Theo. & $\boldsymbol{M} \boldsymbol{w}\left(\mathbf{g} \mathbf{~ m o l}^{-\mathbf{1}}\right)$ & PDI \\
\hline PRSM & 9 & 94 & 19757 & 19230 & 25487 & 1.29 \\
RSMAC 1 & 9 & 83 & 18336 & 16979 & 26405 & 1.44 \\
RSMAC 2 & 9 & 77 & 17104 & 15752 & 26169 & 1.53 \\
RSMAC 3 & 9 & 73 & 16268 & 14934 & 26842 & 1.65 \\
\hline
\end{tabular}

Theoretical molecular weight is calculated by using Equation 1: 

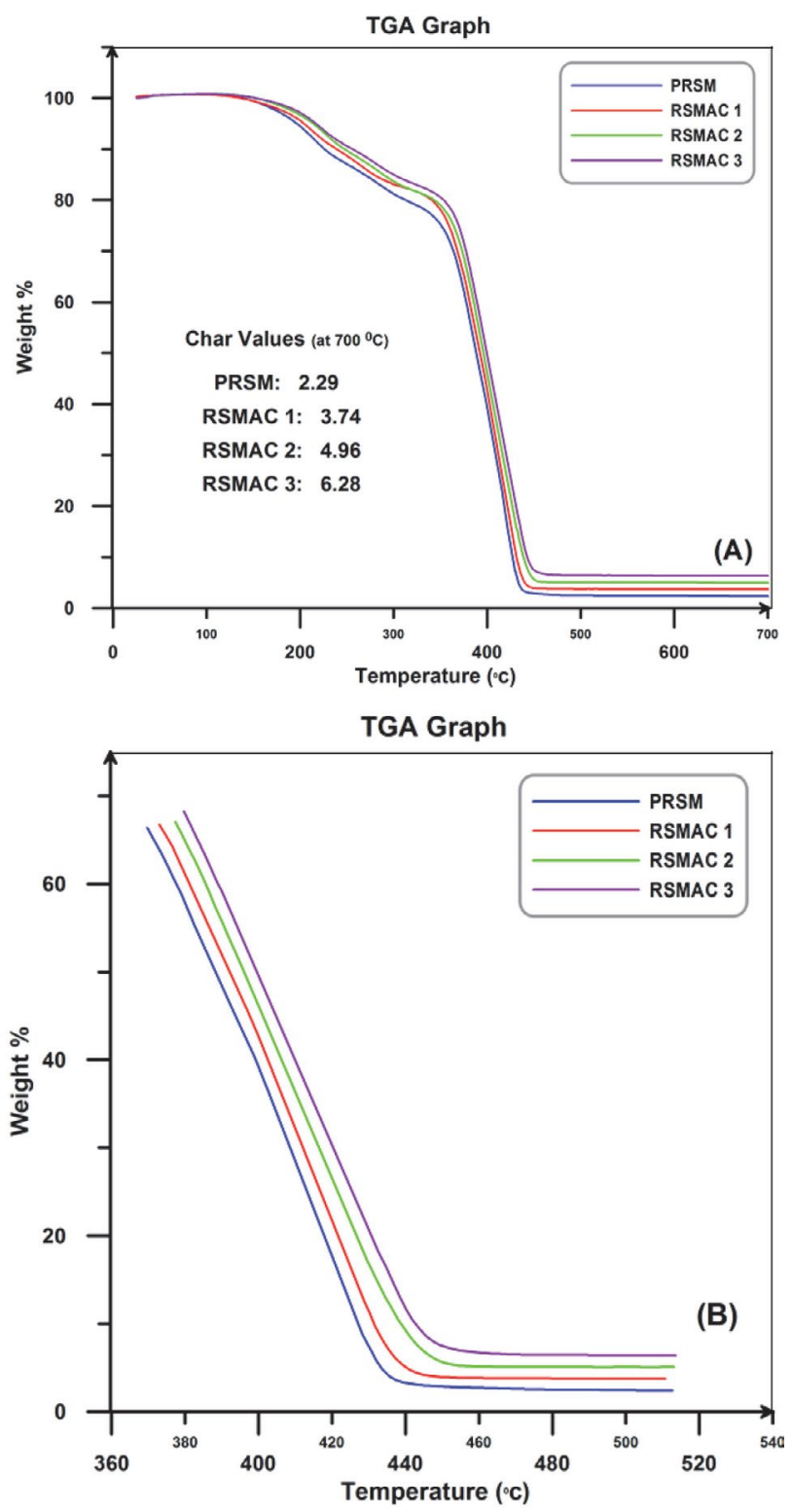

Figure 10. TGA thermograms of the PRSM and RSMAC 1-3

provements in thermal stabilities can be obtained (thermal stability: PRSM $<$ RSMAC $1<$ RSMAC $2<$ RSMAC 3 ). Except the main degradation step in the TGA graphs (at the temperatures above $350{ }^{\circ} \mathrm{C}$ ) that is attributed to the degradation of the synthesized copolymer and its nanocomposites, some other degradation can be also recognized. This degradation in the lower temperatures is ascribed by evaporation of water molecules and volatile materials such as residual monomers and HMDS.

Extracted data from TGA are graphically illustrated in figure 11. Degradation temperature of the samples versus amount of degradation is employed to show that addition of H-SAN in the copolymer matrix, results in an improvement of thermal stabilities of the nanocomposites ( $\mathrm{T}_{\mathrm{X}}$ : temperature threshold at which $\mathrm{X} \%$ of neat copoly-

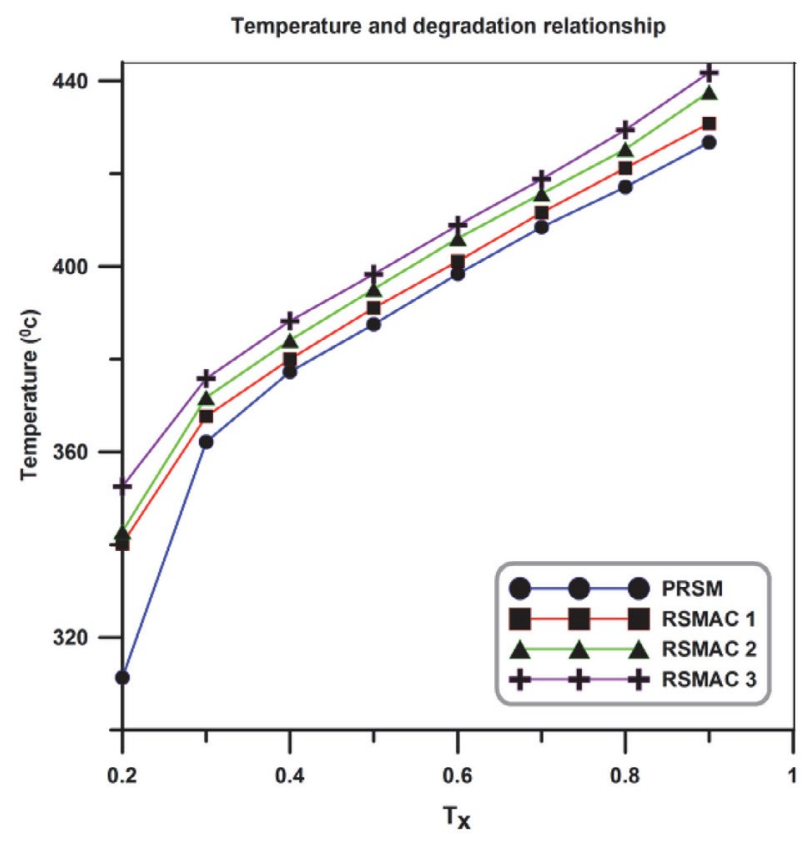

Figure 11. Graphical illustration of temperature and degradation relationship

mer and its nanocomposites is degraded). Char values at $700{ }^{\circ} \mathrm{C}$ are also reported in the figure 10 .

TGA results demonstrate that incorporation of H-SAN in the copolymer matrix leads to improvements in thermal stabilities. This improvement can be ascribed by using inorganic nature of the H-SAN. Modified silica aerogel nanoparticles as inorganic nano-filler can result in higher thermal stabilities of the RSMAC 1-3 in comparison with the PRSM. ${ }^{36}$ Absorption of the introduced gas (in oxygen atmosphere) in the porous structure of the incorporated nano-filler (H-SAN is classified as mesoporous materials) may be considered as another factor for increment of thermal stabilities of the nanocomposites in comparison with the PRSM. ${ }^{33}$

Improvement in thermal stability may be ascribed by inorganic nature of the incorporated nano-filler. H-SAN as inorganic nano-filler that are incorporated and dispersed within the copolymer matrices can result in improvement of thermal stability of the nanocomposites in comparison with the neat copolymer. ${ }^{36}$ Moreover, since the synthesized nano-filler is a member of mesoporous materials family it can absorb introduced gas (in $\mathrm{O}_{2}$ atmosphere) can also results in increment of thermal stability of the nanocomposites. Finally, because of the three-dimensional network structure of the H-SAN, these nanoparticles can not be appropriately dispersed and therefore can not significantly improve thermal stabilities of the nanocomposites. $^{37}$

Evaluation the effect of the H-SAN on the chain confinement and also determination of glass transition temperature $\left(\mathrm{T}_{\mathrm{g}}\right)$ are performed by DSC analysis. DSC curves of the PRSM and RSMAC 1-3 are presented in figure 12 . 


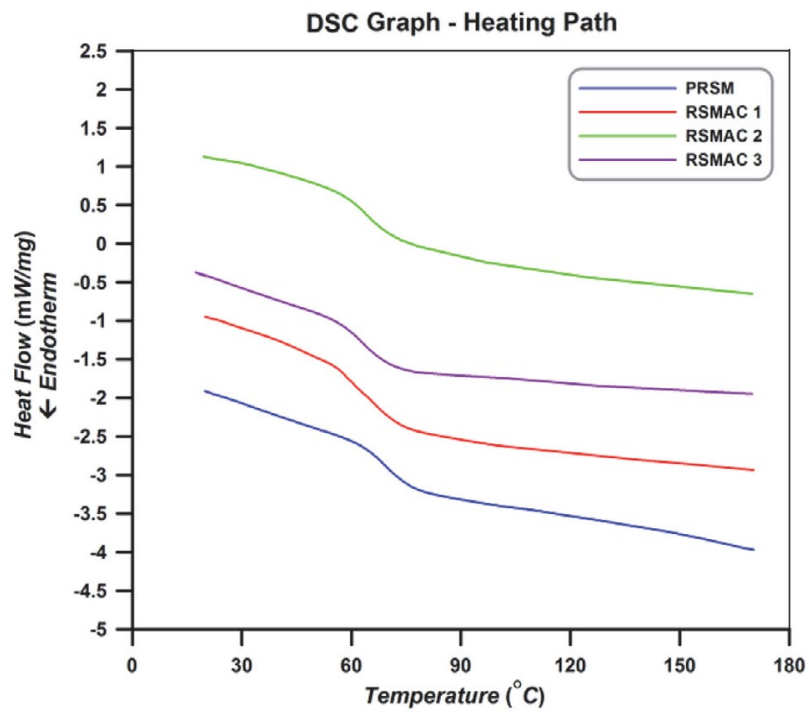

Figure 12. DSC Thermograms of the PRSM and RSMAC 1-3

Although the samples are heated from room temperature to $220^{\circ} \mathrm{C}$ to remove their thermal history, cooling path of the analysis in the temperature range of $20-170^{\circ} \mathrm{C}$ is displayed in this figure.

According to the figure 12, an obvious inflection in the cooling path are occurred which shows $T_{g}$ values of the PRSM and RSMAC 1-3. In addition, amorphous structures of the synthesized samples can be also concluded. Extracted $\mathrm{T}_{\mathrm{g}}$ values of the samples from DSC graphs (in the cooling path) are summarized in table 3.

Table 3. Tg values of the PRSM and RSMAC 1-3

\begin{tabular}{lccc}
\hline Sample & $\mathbf{M}_{\mathbf{n}}\left(\mathbf{g ~ m o l}^{-\mathbf{1}}\right)$ & PDI & $\mathbf{T}_{\mathbf{g}}\left({ }^{\circ} \mathbf{C}\right)$ \\
\hline PRSM & 19757 & 1.29 & 70.3 \\
RSMAC 1 & 18336 & 1.44 & 67.4 \\
RSMAC 2 & 17104 & 1.53 & 65.3 \\
RSMAC 3 & 16268 & 1.65 & 63.5 \\
\hline
\end{tabular}

According to the table 3, PRSM presents higher Tg value in comparison with the other samples (RSMAC 1-3). By incorporating of the H-SAN in the copolymer matrix a decrement in Tg value was happened (Tg: RSMAC $3<$ RSMAC $2<$ RSMAC $1<$ PRSM). Decrement in Tg values by adding $\mathrm{H}-\mathrm{SAN}$ in the copolymer matrix is related to the reduction of the packing of the copolymer chains. By dispersing H-SAN within the copolymer matrix, packing of the copolymer chains will be reduced and therefore copolymer chains can obtain more segment mobilities in which results in decrement of $\mathrm{Tg}$ values. In addition, due to the three-dimensional network structure of the H-SAN these nanoparticles can not appropriately dispersed within the copolymer matrix and therefore some free volume spaces for the dangling copolymer chains may be created. This is also responsible for more segment mobilities of the copolymer chains which in turn results in $\mathrm{T}_{\mathrm{g}}$ reduction. Moreover, according to the table 2, by increasing H-SAN in the copolymer matrix an increment in PDI value and also a decrement in $\mathrm{Mn}$ are observed. These parameters should be also considered since decrease in Mn and increment of PDI values may cause reduction of Tg values. ${ }^{38-39}$ Previous studies indicate that $\mathrm{Tg}$ values can be changed by addition of low volume of different nano-fillers. ${ }^{40-41}$ Reduction of $\mathrm{Tg}$ value by incorporating alumina nanoparticles as a nano-fillers was also reported by Schadler et al. ${ }^{42}$

\section{Conclusions}

Tailor-made random poly (styrene-co-methyl methacrylate) and its different nanocomposites in the presence of H-SAN were synthesized by in situ SR\&NI ATRP. Porous and spongy structure, spherical shape and high surface are some unique properties of the prepared H-SAN. SR\&NI ATRP of styrene and methyl methacrylate in the presence of H-SAN results in a decrease of conversion from 94 to $73 \%$. Moreover, molecular weight of the random copolymer chains decrease from 19757 to 16268 g.mol ${ }^{-1}$ and PDI values increase from 1.29 to 1.65 . Improvement in thermal stability of the nanocomposites and decreasing $\mathrm{T}_{\mathrm{g}}$ values from 70.3 to $63.5^{\circ} \mathrm{C}$ was also obtained by addition of $3 \mathrm{wt} \%$ of the H-SAN.

\section{References}

1. F. Audouin, H. Blas, P. Pasetto, P. Beaunier, C. Boissie`re, Macromol. Rapid Commun. 2008, 29, 914-921.

DOI:10.1002/marc.200800179

2. M. Alexandre, P. Dubois, Mater. Sci. Eng. 2000, 28, 1-63. DOI:10.1016/S0927-796X(00)00012-7

3. L. Wei, N. Hu, Y. Zhang, Materials 2010, 3, 4066-4079. DOI: $10.3390 / \mathrm{ma} 3074066$

4. H. Zou, S. Wu, J. Shen, Chem. Rev. 2008, 108, 3893-3957. DOI: $10.1021 / \mathrm{cr} 068035 \mathrm{q}$

5. S. L. Burkett, N. Ko, N. D. Stern, J. A. Caissie, D. Sengupta, Chem. Mater. 2006, 18, 5137-5143.

DOI: $10.1021 / \mathrm{cm} 0614517$

6. X. Fu, S. Qutubuddin, Polymer 2001, 42, 807-813. DOI:10.1016/S0032-3861(00)00385-2

7. J. M. Brown, D. Curliss, R. A. Vaia, Chem. Mater. 2000, 12, 3376-3384. DOI:10.1021/cm000477+

8. F.Hussain, M. Hojjati, M. Okamoto, R.E. Gorga, J. Compos. Mater. 2006, 40, 1511-1575. DOI:10.1177/0021998306067321

9. S. Varghese, J. Karger-Kocsis, Polymer 2003, 44, 4921-4927. DOI:10.1016/S0032-3861(03)00480-4

10. J. Pyun, K. Matyjaszewski, Chem. Mater. 2001, 13, 3436-3448. DOI:10.1021/cm011065j

11. Y. Fazli, H. Alijani, K. Khezri, Adv. Polym. Technol. 2016, 35, 21549-21558. DOI:10.1002/adv.21549 
12. N. Gupta, W. Ricci, J. Mater. Proces. Technol. 2008, 198, 178182. DOI:10.1016/j.jmatprotec.2007.06.084

13. D. J. Boday, R. J. Stover, B. Muriithi, M. W. Keller, J. T. Wertz, K. A. D. Obrey, D. A. Loy, ASC Appl. Mater. Interfaces 2009, 1, 1364-1369. DOI:10.1021/am900240h

14. Y. Fazli, H. Alijani, K. Khezri, J. Inorg. Organomet. Polym. 2015, 25, 1189-1199. DOI:10.1007/s10904-015-0227-0

15. Y. Tao, M. Endo, K. Kaneko, Rec. Pat. Chem. Eng. 2008, 1, 192-200. DOI:10.2174/1874478810801030192

16. F. Shi, L. Wang, J. Liu, Mater. Let. 2006, 60, 3718-3722. DOI:10.1016/j.matlet.2006.03.095

17. K. Khezri, Y. Fazli, High Temp. Mater. Proc. 2016, 36, 955-962

18. S. Mulik, C. Sotiriou-Leventis, G. Churu, H. Lu, N. Leventis, Chem. Mater. 2008, 20, 5035-5046.

DOI:10.1021/cm800963h

19. X. Zhou, L. Zhong, Y. Xu, Inorg. Mater. 2008, 44, 976-979. DOI:10.1134/S0020168508090148

20. P. B. Sarawade, J-K. Kim, A. Hilonga, H. T. Kim, Solid State Sci. 2010, 12, 911-918.

DOI:10.1016/j.solidstatesciences.2010.01.032

21. L. D. Gelb, J. Phys. Chem. C 2007, 111, 15792-15802. https://doi.org/10.1021/jp0737505

22. K. Min, M. Li, K. Matyjaszewski, J. Polym. Sci. Part A: Polym. Chem. 2005, 43, 3616-3622. DOI:10.1002/pola.20809

23. M. Li, K. Min, K. Matyjaszewski, Macromolecules 2004, 37, 2106-2112. DOI:10.1021/ma035284x

24. D. J. Boday, P. Y. Keng, B. Muriithi, J. Pyun, D. A. Loy, J. Mater. Chem. 2010, 20, 6863-6865. DOI:10.1039/c0jm01448f

25. M. Sarsabili, K. Kalantari, K. Khezri, J. Therm. Anal. Calorim. 2016, 126, 1261-1272. DOI:10.1007/s10973-016-5641-1

26. Y. W. Chen-Yang, Y. L. Wang, Y. T. Chen, Y. K. Li, H. C. Chen, H. Y. Chiu, J. Power Sour. 2008, 182, 340-348.

DOI:10.1016/j.jpowsour.2008.04.001

27. D. J. Boday, R. J. Stover, B. Muriithi, M. W. Keller, J. T. Wertz, K. A. D. Obrey, D. A. Loy, ASC Appl. Mater. Interfaces 2009, 1, 1364-1369. DOI:10.1021/am900240h
28. A. Costela, I.G. Moreno, C. Go'mez, O. Garci'a, R. Sastre, A. Roig, E. Molins, J. Phys. Chem. B 2005, 109, 4475-4480. DOI:10.1021/jp040714m

29. K. Khezri, M. Ghasemi, Y. Fazli, Z. Phys. Chem. 2018, 232, 471-487.

30. K. Khezri, Y. Fazli, Polym. Sci. Ser. B 2017, 59, 109-116. DOI:10.1134/S1560090417010092

31. Y. Fazli, K. Khezri, J. Polym. Res. 2018, 25, 9-19 DOI:10.1007/s10965-017-1405-2

32. M. Karimi, S. Davoudizadeh, S. Bahadorikhalili, K. Khezri, $Z$. Phys. Chem. DOI:10.1515/zpch-2018-1202.

DOI:10.1515/zpch-2018-1202

33. M. Sarsabili, R. Rahmatolahzadeh, SA. Shobeiri, M. Hamadanian, A. Farazin, K. Khezri, Polym Adv Technol. 2018, 29, 424-432. DOI:10.1002/pat.4131

34. K. Khezri, Y. Fazli, J. Thermoplast. Compos. Mater. DOI: $10.1177 / 0892705718805128$

35. S. Davoudizadeh, M. Sarsabili, K. Khezri, Z. Phys. Chem. 2017, 231, 1543-1558. DOI:10.1515/zpch-2016-0812

36. K. Khezri, H. Alijani, Y. Fazli, Acta Chim. Slov. 2018, DOI: 10.17344/acsi.2018.4331. DOI:10.17344/acsi.2018.4331

37. K. Khezri, H. Alijani, Y. Fazli, Z. Phys. Chem. 2016, 230, $111-$ 129.

38. K. Khezri, H. Mahdavi, Micropor. Mesopor. Mater. 2016, 228, 132-140. DOI:10.1016/j.micromeso.2016.03.022

39. Y. Fazli, K. Khezri, Colloid Polym Sci 2017, 295, 247-257. DOI:10.1007/s00396-016-3997-1

40. F. Chen, A. Clough, B.M. Reinhard, M.W. Grinstaff, N. Jiang, T. Koga, O.K.C. Tsui, Macromolecules 2013, 46, 4663-4670. DOI:10.1021/ma4000368

41. B. Natarajan, Y. Li, H. Deng, L.C. Brinson, L.S. Schadler, Macromolecules 2013, 46, 2833-2841.

DOI:10.1021/ma302281b

42. B. J. Ash, R. W. Siegel, L. S. Schadler, J. Polym. Sci. Part B: Polym. Phys. 2004, 42, 4371-4388.

https://doi.org/10.1002/polb.20297

\section{Povzetek}

Tehniko SR\&NI ATRP (polimerizacija s prenosom atoma (ATRP); simultaneous reverse and normal initiation (SR\&NI)) smo uporabili za kopolimerizacijo stirena in metil metakrilata $\mathrm{v}$ prisotnosti aerogela na osnovi nanodelcev silicijevega dioksida (H-SAN) in z dodatkom heksametildisilizana (HMDS). Preučevali smo vpliv dodatka aerogela H-SAN na samo kopolimerizacijo in termične lastnosti produktov. Produkte smo karakterizirali z vrstično elektronsko mikroskopijo (SEM) in presevno elektronsko mikroskopijo (TEM) in jim z uporabo dušika določili adsorpcijske in desorpcijske izorterme. Konverzijo in molekulsko maso smo določili s plinsko kromatografijo (GC) in velikostno izključitveno kromatografijo (SEC). Dodatek 3 ut\% H-SAN je vodil v zmanjšanje pretvorbe s $94 \%$ na $73 \%$. Molekulska masa polimernih verig se je znižala od $19500 \mathrm{~g} \mathrm{~mol}^{-1}$ na $16000 \mathrm{~g} \mathrm{~mol}^{-1}$. Indeks polidisperznosti se je povečal z 1,29 na 1,65. Linearno povečanje $\ln \left(\mathrm{M}_{0} / \mathrm{M}\right)$ s časom za vse vzorce nam daje vpogled v proces kolpolimerizacije. Povečano termično stabilnost nanokompozita smo dokazali s termogravimetrično analizo (TGA). Rezultati diferenčne dinamične kalorimetrije (DSC) kažejo na znižanje temperature steklastega prehoda $\left(\mathrm{T}_{\mathrm{g}}\right) \mathrm{s} 70,3^{\circ} \mathrm{C}$ na $63,5^{\circ} \mathrm{C}$ v primeru dodatka 3 ut\% aerogela $\mathrm{H}-\mathrm{SAN}$. 